\title{
III.
}

\section{Eclampsia and Nephrectomy.*}

\author{
By Spencer Sheill, M.R.C.P. (Dublin), \\ Ex-Assistant-Master, Coombe Maternity Hospital.
}

Ir was a strange but interesting coincidence that Dr. J. Haig Ferguson, of Edinburgh, should have published in this Joorsal of March last details of a case of pregnancy in a patient with but one kidney, just about the same time as I read before the Obstetrical Section of the Royal Academy of Medicine in Ireland what I might term the "grand finale" of a somewhat similar case. Under the title of "A chart representing three years in the life of an eclamptic," I endeavoured faithfully to record the three years of married life of a patient from whom one kidney had been previously removed for tuberculosis. The nephrectomy was performed in the year 1900, and in 1904 she married and soon became pregnant. It was not until March 1905, that the patient came under my care; she was then recovering from an eclamptic seizure and was about six months pregnant. Morphia, with the general treatment usual in such cases, was adopted successfully, for after seven severe seizures the fits ceased. The diagnosis of death of the foetus was then made, and taking into account the presence of great odema, much albumen, scanty urine, and only one kidney, past experience in such cases prompted me to perform induction of labour. The operation was rapidly successful. The baby was dead. The patient made a quick recovery. Fuller details of this case were published in the British Mefical Journal of June 24th, 1905, together with four other cases of "Labour induction."

In August of the same year the patient again consulted me. She was pregnant about three months and a half. Examination of the urine showed commencing kidney failure, the urea was decreasing in amount and albumen was present. Her legs were cedematous. Under the influence of a purely milk diet, diuretics, etc., she improved greatly, but during the following December the albumen returned in the proportion of $1-1000$. In spite of rest and all treatment the symptoms of kidney insufficiency increased in severity, until on the 26th of December her face became swollen. One week later the urine was very scanty and boiled solid, and the patient was becoming dull and stupid in manner. The fotal heart was heard. Nothing now seemed to improve her condition, so I decided to induce labour as

* Read before the section of Obstetrics at the Royal Academy of Medicine in Ireland, April 12th, 1907. 
she was 8 months pregnant and there was a prospect of saving the child. It also appeared to me the only chance for the mother.

Accordingly, on the 8th January, this was done, and a living male child was born (as I write, this child is alive and healthy). Three hours after the birth of the infant she had a severe eclamptic seizure, she was promptly put under the morphia treatment, and made a rapid recovery with no return of the fits. The mother nursed this infant for six months and enjoyed excellent health. The urine, which had fallen to $14 \mathrm{fl}$. oz. in 24 hours, in three days rose to $60 \mathrm{fl}$. oz.

By February there was no trace of albumen in the urine.

At this time I spoke very plainly to the patient and her husband and relations regarding the dangers of another pregnancy, but my advice was of no avail, for on the 16th of the following November I found her two months advanced in her third pregnancy. Her remaining kidney was now much enlarged, very tender, and very movable, and it could easily be felt by the patient herself. The urine was scanty and contained albumen. She had eye symptoms which suggested severe intoxication of nerve centres. Ten days later the amount of urine in 24 hours fell to $26 \mathrm{fl}$. oz. Dr. Boxwell, of the Meath Hospital, kindly tested a sample and reported urea $5 \frac{1}{2}$ grains per fluid ounce and albumen 0.15 per cent. The advisability of inducing abortion was considered on account of the critical condition of the patient, and on the 5th December, when the urine passed fell to $14 \mathrm{fl}$. oz., and the urea contained was but $7 \frac{1}{2}$ grains per fluid ounce (the albumen remained at $0 \cdot 15$ per cent.), with the aid of Drs. Stokes and Boxwell, I performed the operation under anæsthesia at one sitting, removing a fœtus and placenta of about 3 months' development. The patient made a rapid and uneventful recovery, and 48 hours later passed $40 \mathrm{fl}$. oz. of urine containing but a trace of albumen and much urea. On weighing over carefully all the circumstances of the case I believed that the weight of evidence was against this woman ever carrying through another pregnancy successfully. On three occasions her kidney had shown that although quite competent to cope with the demands of the system under ordinary conditions it was utterly unable to rise to the occasion of a pregnancy, and each time showed less reserve force; for, although it was the second pregnancy that I brought to a successful issue, yet during the whole of that gestation period she was under special care and treatment, whilst in the first the alarm was only sounded on the advent of an eclamptic seizure at six months. Probably this one might have been carried through satisfactorily had she been under treatment sufficiently early. As for the third and last her condition was so alarming at two months that all efforts were required to save the patient herself.

These reasons and the fact that she had a living, strong child, prompted me to recommend to herself and to her husband that she 
Antecedent history of patient.

$\underline{I 900 .}$

Left Renal Tuberculosis-Nephrectomy.

rgo4. Marriage

Ist Pregnancy

March, I905. Eclampsia

(6 mos. preg.)

Induction of Labour

August , 2nd Pregnancy

Usual treatment

Dec. " In spite of treatment

Jan. Ig06. Induction of Labour (at 8 months) Eclampsia

Sept. " 3rd Pregnancy

Nov. " Kidney rapidly failing

Dec. " Uterus emptied (at 3 months)

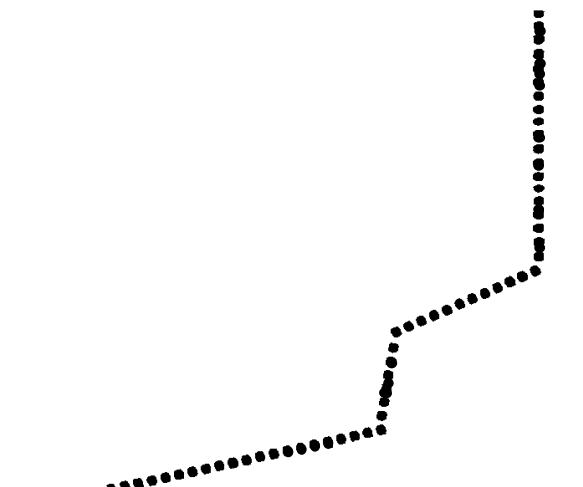


should submit to an operation for the prevention of possible future pregnancies. This they agreed to, and on the 24th of January 1907, a portion of her Fallopian tubes was resected.

This case appears to me to raise some interesting points. The question of advising against marriage at all, or of its postponement till the menopause is, I think, hardly to be entertained, for it is unlikely to be seriously considered. But I agree with Dr. Ferguson in the opinion that we ought to advise against marriage sooner than, say, three or four years after nephrectomy in order to allow of a physiological hypertrophy of the remaining kidney.

The induction of labour in threatened eclampsia if the child is: viable, and if the mother's condition resists less radical treatment, has been successful in my hands on several occasions. It is, in my. opinion, the best treatment for all concerned.

The total amount of urea excreted by the kidney in 24 hours is a very important guide; had I gone by the amount of albumen alone: (which never rose beyond 0.15 per cent. in the last pregnancy) I should have had a very false notion of the work done by the kidney and of the intensity of the intoxication of the patient, for although we cannot estimate the amount of toxins present except by their effects, we know by experience that as urea excretion diminishes: markedly, so will symptoms of toxæmia assert themselves.

Then the important question of the absolute prevention of further pregnancies by operation presents itself. If the patient has shown her utter incapability of carrying a pregnancy through successfully I believe resection of the tubes is to be strongly advised in the interests of all concerned. 